\title{
A Point Mutation in Transthyretin Increases Affinity for Thyroxine and Produces Euthyroid Hyperthyroxinemia
}

\author{
Alan C. Moses,“ Harold N. Rosen, “ David E. Moller," Sayumi Tsuzaki, „ James E. Haddow,” Joseph Lawlor," \\ Juris J. Liepnieks," William C. Nichols," and Merrill D. Benson" \\ *Diabetes and Thyroid Units, Charles A. Dana Research Institute and the Harvard-Thorndike Laboratories of Beth Israel Hospital, \\ Boston, Massachusetts 02215; ${ }^{\ddagger}$ The Foundation for Blood Research, Scarborough, Maine 04074; ${ }^{\S}$ Lawlor Biomedical Associates, \\ Arlington, Massachusetts 02174; and "The Department of Medicine, Indiana University School of Medicine, Indianapolis, Indiana 46202
}

\begin{abstract}
In a family expressing euthyroid hyperthyroxinemia, an increased association of plasma thyroxine $\left(T_{4}\right)$ with transthyretin (TTR) is transmitted by autosomal dominant inheritance and is secondary to a mutant TTR molecule with increased affinity for $T_{4}$. Eight individuals spanning three generations exhibited the abnormality. Although five of eight individuals had elevated total $T_{4}$ concentrations, all affected individuals were clinically euthyroid and all had normal free $T_{4}$ levels. Purified TTR from the propositus had an affinity for ${ }^{125} I-T_{4}$ three times that of control TTR. Exons 2, 3, and 4 (representing $>97 \%$ of the coding sequence) of the TTR gene of DNA prepared from the propositus' peripheral blood leukocytes were amplified using the polymerase chain reaction (PCR) and were sequenced after subcloning. Exons 2 and 3 were indistinguishable from normal. In $50 \%$ of clones amplified from exon 4 , a substitution of adenine (ACC) for guanine (GCC) in codon 109 resulted in the replacement of threonine-for-alanine, a mutation confirmed by amino acid sequencing of tryptic peptides derived from purified plasma TTR. The adenine-for-guanine substitution abolishes one of two Fnu $4 \mathrm{H}$ I restriction sites in exon 4. PCR amplification of exon 4 of TTR and restriction digestion with Fnu $4 \mathrm{H}$ I confirmed that five affected family members with increased binding of ${ }^{125} \mathrm{I}-\mathrm{T}_{4}$ to TTR are heterozygous for the threonine 109 substitution that increases the affinity of this abnormal TTR for $T_{4}$. (J. Clin. Invest. 1990. 86:2025-2033.) Key words: thyroxine binding proteins • prealbumin • hyperthyroidism • genetic diseases - dysalbuminemic hyperthyroxinemia
\end{abstract}

\section{Introduction}

Transthyretin (TTR), ${ }^{1}$ also known as thyroxine binding prealbumin, is a serum protein of hepatic origin that transports between 20 and $30 \%$ of serum thyroxine in normal individuals. We and others previously have described clinically euthy-

Address correspondence and reprint requests to Dr. Alan C. Moses, Room SL-436, Department of Medicine, Beth Israel Hospital, 330 Brookline Ave., Boston, MA 02215.

Received for publication $24 \mathrm{May} 1990$ and in revised form $10 \mathrm{Au}$ gust 1990.

1. Abbreviations used in this paper: PCR, polymerase chain reaction; $\mathrm{T}_{4}$, thyroxine; TBG, thyroxine binding globulin; TTR, transthyretin.

J. Clin. Invest.

(C) The American Society for Clinical Investigation, Inc.

0021-9738/90/12/2025/09 \$2.00

Volume 86, December 1990, 2025-2033 roid individuals with hyperthyroxinemia secondary to an increased association of thyroxine $\left(\mathrm{T}_{4}\right)$ with TTR (1-7). These subjects are often incorrectly diagnosed, and subjected to unnecessary laboratory tests and inappropriate therapy (1). Several investigators have demonstrated increased total $T_{4}$ in clinically euthyroid subjects who have marked elevations of circulating transthyretin (2-4). In 1982, we reported a patient with euthyroid hyperthyroxinemia and suggested that the elevated serum $T_{4}$ resulted from an abnormal TTR with increased affinity for $T_{4}$ rather than from an elevated concentration of TTR. Lalloz et al. $(5,6)$ and Croxson et al. (7) have reported other patients with a similar abnormality. In this report, we have investigated in greater detail the mechanisms underlying the hyperthyroxinemia in the kindred reported by us and describe a point mutation in the TTR gene that appears to be responsible for the greater affinity of this molecule for $\mathrm{T}_{4}$.

\section{Methods}

General hormone and protein assays. Total $\mathrm{T}_{4}$ (Corning Medical, Medfield, MA), $\mathrm{T}_{3}$ resin uptake (Amersham Corp., Arlington Heights, IL), total $\mathrm{T}_{3}$ (Clinical Assays, Cambridge, MA), and thyroxine binding globulin (TBG, Corning Medical) were measured using standard commercially available kits. Free $T_{4}$ was measured both by dialysis and by a two-step direct immunoassay procedure (Clinical Assays). TTR concentrations in serum were measured by rocket immunoelectrophoresis (1). Comparisons between groups were performed by the Student's unpaired $t$ test and statistical significance was arbitrarily defined at $P$ $<0.05$. Statistical significance of differences between the affinity of mutant TTR and normal TTR was determined by the Mann-Whitney test.

Protein binding and sequencing studies. 27 relatives of the proband were screened for an increase in $T_{4}$ associated with TTR by three assays: $(a) \mathrm{T}_{4}$ immunoprecipitation by anti-TTR $\operatorname{IgG},(b)$ a modified $T_{4}$-loaded $T_{4}$ charcoal-uptake test (8), and (c) serum paper electrophoresis after incubation of sera with ${ }^{125} \mathrm{I}_{-} \mathrm{T}_{4}(1)$. Sera from these subjects were also compared with sera from six normal unrelated subjects aged 25-50 yr.

For the immunoprecipitation assay, $100 \mu$ of a 1:25 dilution of sera in PBS were incubated with ${ }^{125} \mathrm{I}-\mathrm{T}_{4}\left(6 \times 10^{-12} \mathrm{M}\right.$; SA $4,400 \mathrm{Ci} / \mathrm{mmol}$ New England Nuclear, Boston, MA) in $100 \mu$ l of PBS containing 100 $\mu \mathrm{g} / \mathrm{ml}$ of BSA for $3 \mathrm{~h}$ at $37^{\circ} \mathrm{C} .100 \mu \mathrm{l}$ of a 1:20 dilution of anti-TTR IgG (Atlantic Antibodies, Scarborough, ME) were added before incubation overnight at $4^{\circ} \mathrm{C}$. The TTR-IgG complex was precipitated in the presence of $0.1 \%$ bovine gamma globulin and $10 \%$ (wt/vol, final concentration) $8,000 \mathrm{~mol} \mathrm{wt}$ polyethylene glycol (PEG) for $30 \mathrm{~min}$ at $4^{\circ} \mathrm{C}$ and centrifuged at $3,000 \mathrm{rpm}$ for an additional $30 \mathrm{~min}$ at $4^{\circ} \mathrm{C}$. The supernatant was removed and the pellet was counted in a gamma spectrometer. Data were expressed as a percent of total counts precipitated by anti-TTR. All samples were measured in duplicate in at least three separate assays.

The $\mathrm{T}_{4}$-loaded $\mathrm{T}_{4}$ charcoal-uptake test was performed using a modification of the method of Stockigt et al. (8). In this assay, $10 \mu \mathrm{l}$ of sera was incubated with ${ }^{125} \mathrm{I}-\mathrm{T}_{4}$ in the presence of $10^{-7}$ unlabeled $\mathrm{T}_{4}$, an 
amount sufficient to saturate the high affinity, low capacity $\mathrm{T}_{4}$ binding site on TBG. Samples were incubated for $1 \mathrm{~h}$ at $23^{\circ} \mathrm{C}$ in PBS, pH 7.4, containing $0.1 \%$ gelatin before mixing with $0.5 \mathrm{ml}$ of chilled $1 \%$ Norit A charcoal/0.4\% Dextran 70. Charcoal-bound ${ }^{125} \mathrm{I}_{-} \mathrm{T}_{4}$ was separated by centrifugation at $3,000 \mathrm{rpm}$ for $30 \mathrm{~min}$ at $4^{\circ} \mathrm{C}$. Supernatants containing the protein-bound ${ }^{125} \mathrm{I}-\mathrm{T}_{4}$ were counted for ${ }^{125} \mathrm{I}$. This represents ${ }^{125} \mathrm{I}_{-} \mathrm{T}_{4}$ bound to TTR and albumin.

The electrophoretic distribution of ${ }^{125} \mathrm{I}_{-} \mathrm{T}_{4}$ in sera was measured by

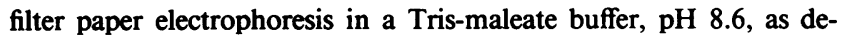
scribed previously (1). 5-mm strips of paper were cut beginning at the origin and counted for ${ }^{125} \mathrm{I}$. Data were expressed as a percentage of total recovered counts associated with TBG, albumin, and TTR, respectively.

TTR purification, competitive binding studies, and protein sequencing. TTR was purified by three-step column chromatography as described previously (9). TTR affinity for thyroxine was assessed with a competitive binding assay using both whole sera (1:25 dilution in PBS) and purified TTR ( $0.5 \mu \mathrm{g} /$ tube), as described above for the immunoprecipitation studies except that replicate samples of sera or purified TTR were incubated with ${ }^{125} \mathrm{I}_{-} \mathrm{T}_{4}\left(6 \times 10^{-12} \mathrm{M}\right)$ in the presence of varying concentrations of unlabeled $T_{4}$. Previous studies (data not presented) demonstrated that the incubation conditions resulted in steady-state binding of ${ }^{125} \mathrm{I}_{-} \mathrm{T}_{4}$ to TTR. TTR-bound ${ }^{125} \mathrm{I}_{-} \mathrm{T}_{4}$ was separated as described above for the immunoprecipitation assay and counted in a gamma spectrometer. Affinity constants were calculated by the method of Scatchard (10). All assays were performed at least three times.

Purified TTR ( $3 \mathrm{mg}$ ) was digested overnight with $2 \%$ trypsin (wt/ $w t$ ), and the resulting peptides were isolated using reverse-phase HPLC. Specific purified tryptic peptides were sequenced in a liquidphase protein sequenator, as previously described (11). Peptides for sequencing were selected based on DNA sequencing of exon 4 as described below.

Enzymatic amplification of genomic DNA and DNA sequencing. Genomic DNA was isolated from peripheral blood leukocytes by phenol/chloroform extraction using standard techniques (12). The TTR gene consists of four exons encoding a protein monomer of 127 amino acids and $14,000 \mathrm{~mol} \mathrm{wt}(13,14)$. Exons 2,3 , and 4 of the TTR gene encode $>97 \%$ of the amino acid sequence and were amplified using the polymerase chain reaction (PCR) with three oligonucleotide primer sets as previously described (11) and producing PCR products of 215,258 , and $190 \mathrm{bp}$, respectively. Exon 1 which encodes only the first three amino-terminal amino acids was not studied $(13,14)$. Each oligonucleotide primer contained a PST-1 restriction enzyme recognition site that was used for subsequent subcloning (15). PCR product DNA fragments were visualized after agarose gel electrophoresis $(1.8 \%$ agarose) in the presence of ethidium bromide. Appropriate length fragments were excised from the gel, extracted with phenol/chloroform, and ethanol precipitated. They were digested with PST1 and ligated into MP-18RF DNA with T4 DNA ligase (Collaborative Research, Bedford, MA) (15). These constructs were used to transform competent JM101 Escherichia coli (15). Single-stranded DNA was isolated from 8 clones derived from exon 2, 10 clones from exon 3, and 8 clones from exon 4 . The DNA was sequenced using the dideoxy chain termination method with modified T7 DNA polymerase (16) (Sequenase Version 2.0; U.S. Biochemical Corp., Cleveland, $\mathrm{OH}$ ).

Screening family members for mutations in the TTR gene using $P C R$ and restriction fragment length polymorphism (RFLP). A point mutation present in four of eight $M-13$ colonies of exon 4 from the proband eliminated one of two restriction sites for the enzyme Fnu $4 \mathrm{H}$ I in exon 4. Based on this observation, we isolated genomic DNA from additional members of the proband's family and subjected the DNA to PCR amplification of exon 4 with the following oligonucleotide primers (see also Fig. 8):

5' oligo: 5' TAG GTG GTA TTC ACA GCC 3'

3' oligo: 5' GTG CCT TTC ACA GGA ATG 3'
These PCR reactions were performed with Taq DNA polymerase (Perkin-Elmer Cetus, Norwalk, CT) for 40 cycles. Denaturation was accomplished at $90^{\circ} \mathrm{C}$ for $30 \mathrm{~s}$, annealing at $55^{\circ} \mathrm{C}$ for $60 \mathrm{~s}$, and extension at $70^{\circ} \mathrm{C}$ for $60 \mathrm{~s}$, except during the last cycle where the extension time was $7 \mathrm{~min}$. Aliquots of the amplified PCR product DNA (100 ng) were digested with $1.5 \mathrm{U}$ of the restriction enzyme Fnu $4 \mathrm{H}$ I (New England Biolabs, Beverly MA), and subjected to electrophoresis in 4\% agarose gels (Nusieve; FMC BioProducts, Rockland, ME). The bands were visualized with ethidium bromide staining and photographed. The mutation predicts fragments of 222 and 35 bp as opposed to 207-, 15-, and 35-bp fragments for the normal gene. Heterozygotes, therefore, are expected to display both 207- and 222-bp fragments (the smaller fragments usually are not visualized using this technique).

\section{Results}

Studies of family members. Of 27 family members screened, 8 demonstrated increased precipitation of ${ }^{125} \mathrm{I}_{-} \mathrm{T}_{4}$ by anti-TTR IgG compared with six normal controls $(27.0 \pm 4.8 \%$ vs. $5.78 \pm 2.0 \%$, respectively, $P<0.0001$; Fig. 1). Affected family members were defined as those in whom the ${ }^{125} \mathrm{I}_{-} \mathrm{T}_{4}$ precipitated by anti-TTR IgG was more than 3 SD greater than the mean obtained in the six normal control subjects, which was $15 \%$. There was no overlap between the affected individuals and the six control subjects. Moreover, there was no overlap between affected and unaffected family members and no difference between unaffected family members and controls (Fig. 1).

In a charcoal $T_{4}$ uptake test in the presence of $10^{-7} \mathrm{M} \mathrm{T}_{4}$, the eight individuals who had increased immunoprecipitation of ${ }^{125} \mathrm{I}_{-} \mathrm{T}_{4}$ by anti-TTR IgG had a decreased percentage of $\mathrm{T}_{4}$
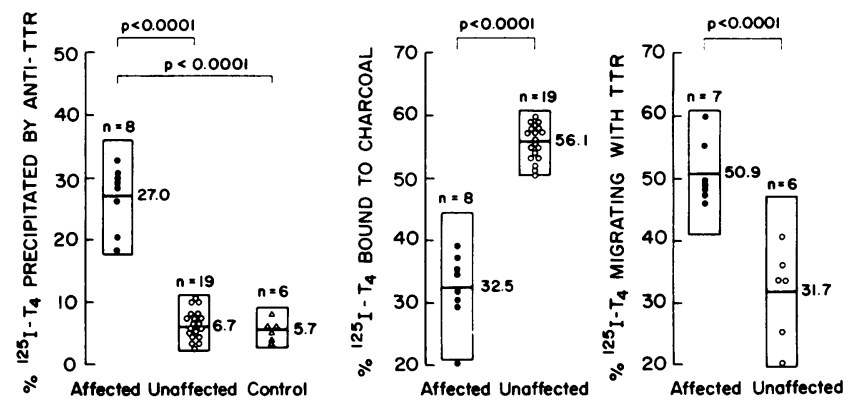

Figure 1. Association of ${ }^{125} \mathrm{I}_{-} \mathrm{T}_{4}$ with TTR: analysis by multiple tests. (Left) Sera from patients with dystransthyretinemic hyperthyroxinemia, from unaffected family members, and from normal controls were incubated with ${ }^{125} \mathrm{I}-\mathrm{T}_{4}$ and precipitated with anti-TTR IgG (see Methods for details). Percent of ${ }^{125} \mathrm{I}_{-} \mathrm{T}_{4}$ precipitated by anti-TTR IgG is indicated for each individual. Any subject with $>15 \%{ }^{125} \mathrm{I}_{-} \mathrm{T}_{4}$ precipitated by anti-TTR IgG arbitrarily was defined as "affected." The mean for the group is indicated and the height of the open bar represents 2 SD around the mean. Statistical differences between groups are indicated. (Center) Sera from affected and unaffected family members were incubated with ${ }^{125} \mathrm{I}_{-} \mathrm{T}_{4}$ and with $10^{-7} \mathrm{M}$ unlabeled $\mathrm{T}_{4}$. Unbound tracer was separated using dextran-coated charcoal (see Methods for details). The percentage of total counts bound by charcoal is indicated for each subject and the mean for the group is shown to the right of each open bar. The height of the open bar represents 2 SD around the mean. (Right) Sera from affected and unaffected subjects were incubated with ${ }^{125} \mathrm{I}_{-} \mathrm{T}_{4}$ and then subjected to paper electrophoresis. Percent of total ${ }^{125} \mathrm{I}_{-} \mathrm{T}_{4}$ migrating with TTR is indicated for each individual studied. The mean for the group is indicated to the right of each open bar. The height of the open bar represents $2 \mathrm{SD}$ around the mean. 

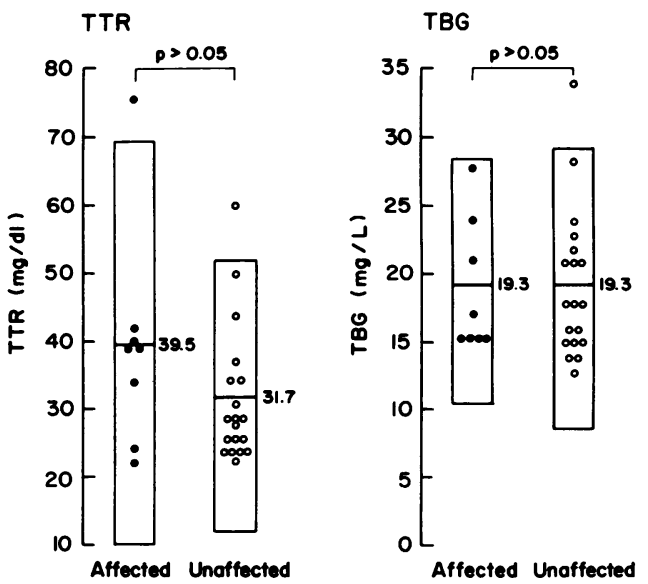

Figure 2. Thyroxine binding protein levels in subjects affected with dystransthyretinemic hyperthyroxinemia and in unaffected family members. TTR concentrations (left) were determined by rocket immunoelectrophoresis and are indicated for each subject studied. The mean for the group is shown to the right of the open bar which represents 2 SD around the mean. TBG concentrations (Right) were determined by radioimmunoassay and are indicated for each of the subjects studied. The mean for the group is shown to the right of the open bar which represents 2 SD around the mean.

bound to charcoal compared with the unaffected family members $(32.5 \pm 5.9 \%$ vs $56.1 \pm 2.5 \%$, respectively, $P<0.0001$; Fig. 1). Since this concentration of unlabeled $\mathrm{T}_{4}\left(10^{-7} \mathrm{M}\right)$ should saturate all available TBG binding sites $\left(K_{a}=10^{9} / \mathrm{M}\right)$, these findings are consistent with affected individuals having an increased association of $T_{4}$ with TTR or with albumin.

Sera from seven of the eight family members with increased ${ }^{125} \mathrm{I}_{-} \mathrm{T}_{4}$ precipitated by anti-TTR IgG were subjected to paper electrophoresis. All seven of these individuals had an increased fraction of $\mathrm{T}_{4}$ migrating with TTR by paper electrophoresis compared with six unaffected family members $(51 \pm 5 \%$ vs. $31.7 \pm 7.6 \%$, respectively, $P<0.009$; Fig. 1$)$ and there was no overlap of TTR associated ${ }^{125} \mathrm{I}_{-} \mathrm{T}_{4}$ between affected and unaffected individuals. There was a corresponding decrease in the amount of ${ }^{125} \mathrm{I}-\mathrm{T}_{4}$ associated with TBG in the affected $(29 \pm 6.8 \%)$ versus the unaffected $(43.8 \pm 4.9 \%)$ family members (data not shown).

We confirmed that the concentration of TTR was not significantly increased in the affected individuals $(39.5 \pm 17 \mathrm{mg} / \mathrm{dl}$ [affected] vs. $31.7 \pm 9.9 \mathrm{mg} / \mathrm{dl}$ [unaffected]; Figs. 2 and 3). Furthermore, there was no correlation between the individual TTR concentrations and ${ }^{125} \mathrm{I}_{-} \mathrm{T}_{4}$ precipitated by anti-TTR IgG (Fig. 3). Serum TBG levels were identical $(19.3 \mathrm{mg} /$ liter, Fig. 2 ) in both the affected and unaffected groups of family members.

Serum $\mathrm{T}_{4}$ was significantly higher in affected than in unaffected family members $(12.5 \pm 1.7$ vs $9.2 \pm 3.2 \mu \mathrm{g} / \mathrm{dl}$ respectively, $P=0.0009)$, as was the free $\mathrm{T}_{4}$ index $(11.8 \pm 2.6 \mathrm{vs}$ $7.76 \pm 2.2$, respectively, $P=0.0002$; Fig. 4). Five of the eight affected patients had serum $\mathrm{T}_{4}$ levels above the upper limit of the normal range $(12 \mu \mathrm{g} / \mathrm{dl})$, although there was considerable overlap between the two groups. Free $T_{4}$ by equilibrium dialysis and by a two-step direct free $T_{4}$ assay was normal in all affected subjects. There was no significant difference in serum $\mathrm{T}_{3}$ levels between affected $(135 \pm 21 \mathrm{ng} / \mathrm{dl})$ and unaffected subjects $(127 \pm 22 \mathrm{ng} / \mathrm{dl})$. The latter finding is not unexpected given the low affinity of TTR for $T_{3}$.

We have used the data from immunoprecipitation of ${ }^{125} \mathrm{I}$ $\mathrm{T}_{4}$ with anti-TTR IgG to investigate the mode of inheritance of this cause of euthyroid hyperthyroxinemia. As shown in Fig. 5, TTR-associated hyperthyroxinemia was identified in two generations and was transmitted as an autosomal dominant trait. These data suggest that affected individuals are heterozygous from a presumed mutation in the TTR gene.

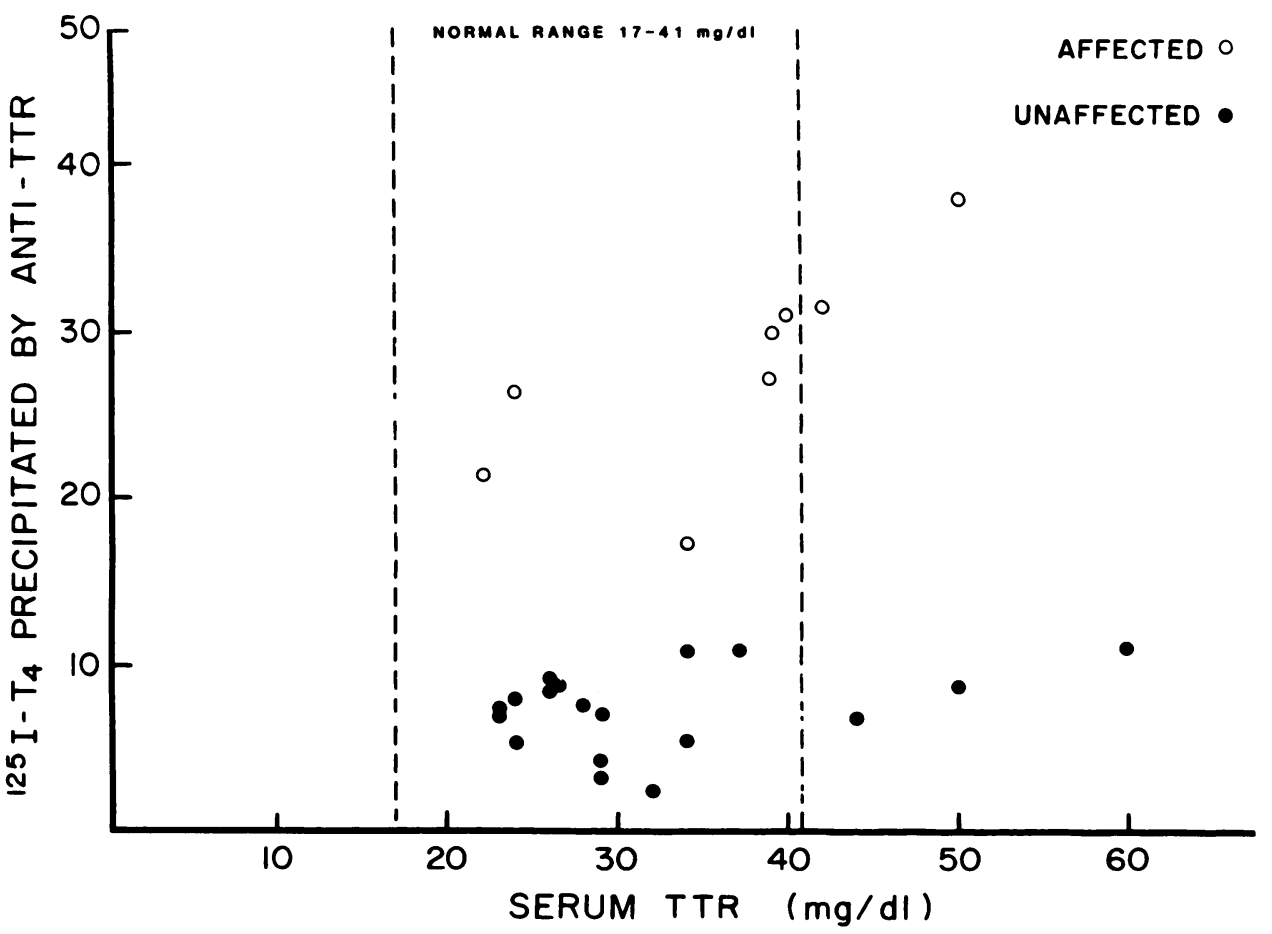

Figure 3. Relation between TTR levels and percent ${ }^{125} \mathrm{I}-\mathrm{T}_{4}$ bound by TTR in subjects affected with dystransthyretinemic hyperthyroxinemia and in unaffected family members. The percentage of total ${ }^{125} \mathrm{I}_{-} \mathrm{T}_{4}$ precipitated by anti-TTR IgG for each individual studied is plotted as a function of that individual's serum TTR concentration as determined by rocket immunoelectrophoresis. Affected individuals are designated by the open symbols and unaffected family members are designated by the solid symbols. The range of normal serum TTR concentrations is indicated by the vertical dashed lines. 

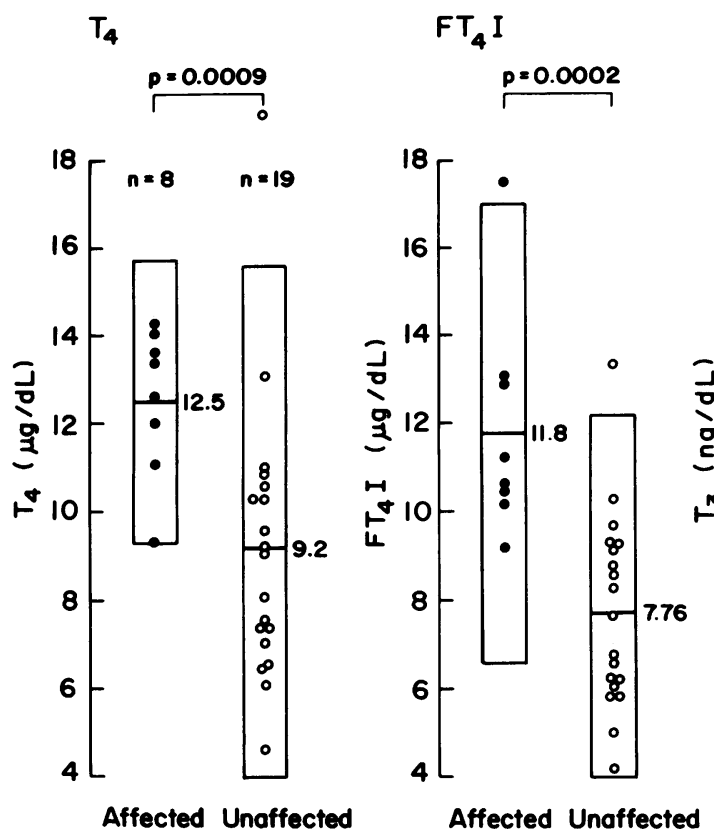

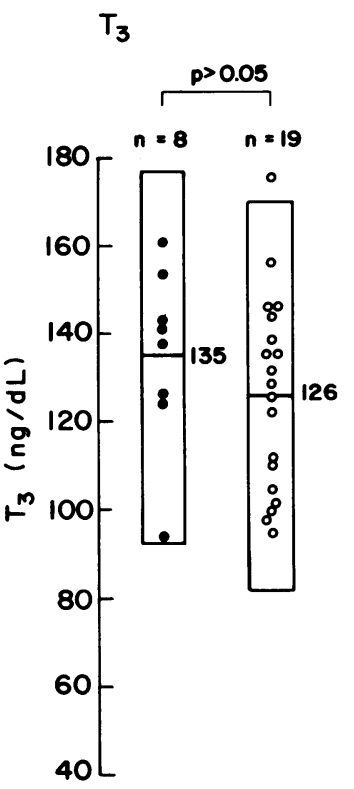

Affected Unaffected
Figure 4. Serum thyroid hormone concentrations in affected and unaffected family members in a kindred with dystransthyretinemic hyperthyroxinemia. (Left) Serum total $\mathrm{T}_{4}$ concentrations are plotted for each affected individual (closed symbols) and for each unaffected family member (open symbols). The mean for the group is indicated to the right of each open bar which represents 2 SD around the mean. Statistical significance is indicated at the top of the panel. (Center) Serum free $\mathrm{T}_{4}$ indices (total $\mathrm{T}_{4} \times \mathrm{T}_{3}$ resin uptake) are plotted for each affected (solid symbols) and unaffected (open symbols) family member. (Right) Serum total $\mathrm{T}_{3}$ concentrations are plotted for each affected (closed symbols) and unaffected (open symbols) family member.
Protein binding studies. The lack of correlation between TTR concentration and ${ }^{125} \mathrm{I}_{-} \mathrm{T}_{4}$ precipitated by anti-TTR IgG suggests that hyperthyroxinemia in these subjects is due to a TTR with increased affinity for $T_{4}$. To confirm this suggestion, we performed equilibrium competitive binding studies with ${ }^{125}$ I-T $_{4}$ and anti-TTR IgG on TTR purified from the proband's plasma and from the plasma of a normal control subject (Fig. 6). As is apparent from the left panel in Fig. 6, the most striking difference between "affected" and normal TTR was the amount of ${ }^{125} \mathrm{I}-\mathrm{T}_{4}$ bound in the absence of unlabeled $\mathrm{T}_{4}$. Scatchard analysis of competitive binding studies comparing purified TTR from the proband to TTR from a normal control revealed that the proband's TTR bound $\mathrm{T}_{4}$ with an affinity approximately three times that of control $\left(K_{a}=3.36 \pm .76[n\right.$ $=6]$ vs. $1.06 \pm 0.036 \times 10^{7} / \mathrm{M}[n=5], P<0.005$; Fig. 6 , right . Parallel studies were performed on whole sera from affected and unaffected family members and the results with whole sera were similar to those obtained with purified TTR (data not shown). In the studies on whole sera, affected and unaffected family members were paired on the basis of similar serum TTR concentrations (data not shown).

Identification of a coding region mutation in the proband's $D N A$. In an effort to identify an anticipated mutation in the proband's TTR gene that could account for the increased affinity of this protein for $T_{4}$, we performed DNA sequencing of TTR exons 2, 3, and 4 following PCR amplification of genomic DNA. Within exon 4, four of eight independent M-13 clones revealed an adenine-for-guanine substitution in the position corresponding to the first base of the triplet codon for amino acid residue 109 (Fig. 7). This finding is consistent with a heterozygous defect which is present in half of the alleles. This mutation encodes threonine (ACC) at this position instead of alanine (GCC) found in normal TTR. The DNA sequence of 8 clones isolated from exon 2 and 10 clones from exon 3 failed to detect any consistent changes from the reported normal TTR cDNA sequence. We did not amplify exon 1, which encodes only the first three amino terminal residues of TTR $(13,14)$.

Direct amino acid sequencing of HPLC-purified tryptic peptides of the propsitus's TTR confirmed a threonine-for-alanine substitution at this location and also confirmed the heterozygous nature of the mutation (Fig. 8). HPLC separation of tryptic peptides generated from the propositus' TTR revealed a peak (11-12*, Fig. 8) not found in wild-type TTR. Amino acid sequence analysis of this peptide (residues 104-114) revealed a sequence of Arg-Tyr-Thr-Ile-Ala-Thr-Leu-Leu-Ser-

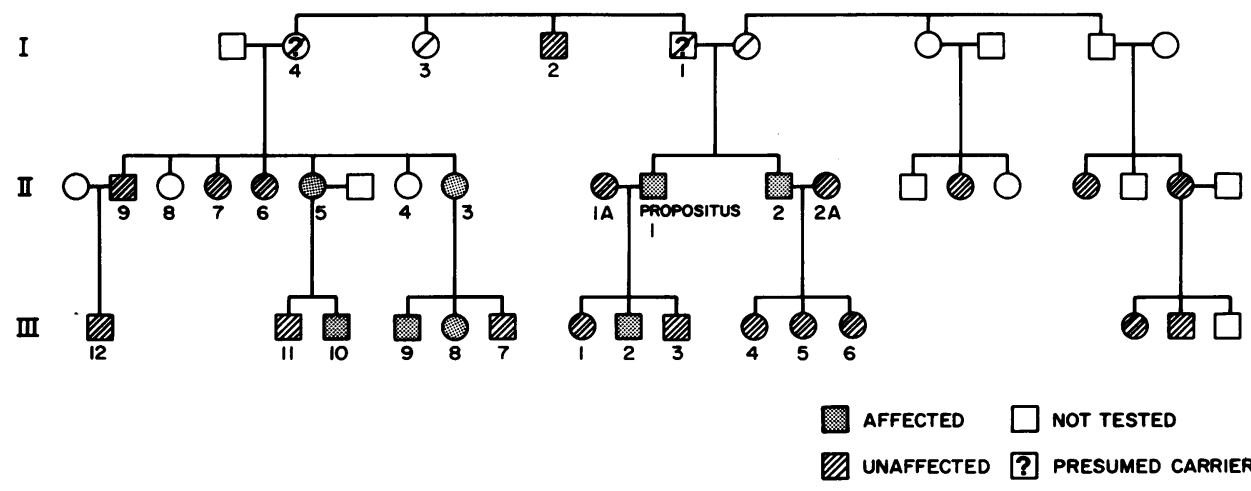

Figure 5. Analysis of kindred with dystransthyretinemic hyperthyroxinemia. Sera from members of three generations were studied by immunoprecipitation with anti-TTR IgG incubated with ${ }^{125} \mathrm{I}-\mathrm{T}_{4}$. Individuals were arbitrarily assigned as affected if the percent ${ }^{125} \mathrm{I}_{-} \mathrm{T}_{4}$ precipitated by anti-TTR IgG was $>3$ SD greater than the mean of six normal controls (see Fig. 1). The symbols with the single diagonal line represent deceased family members. 

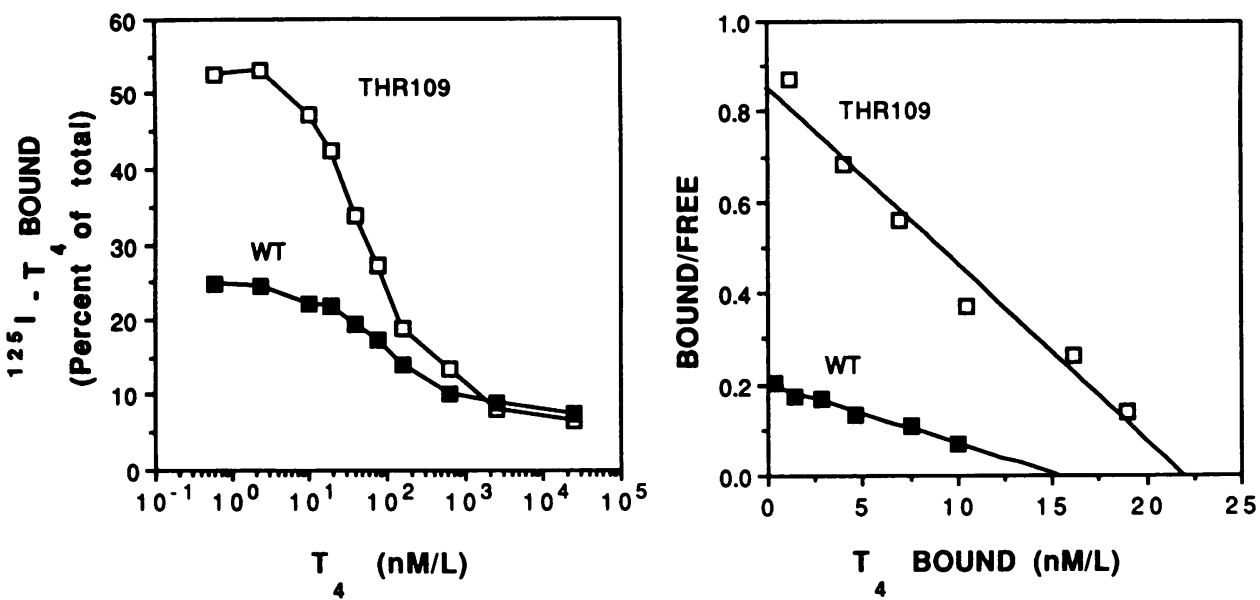

Figure 6. Equilibrium competitive binding of ${ }^{125} \mathrm{I}_{-} \mathrm{T}_{4}$ to TTR purified from the plasma of the proband with euthyroid dystransthyretinemic hyperthyroxinemia and to TTR purified from normal plasma. (Left) Equilibrium competitive binding assay, with each TTR incubated with ${ }^{125} \mathrm{I}-\mathrm{T}_{4}$ and with the indicated concentrations of unlabeled $T_{4}$. Bound ${ }^{125} \mathrm{I}-\mathrm{T}_{4}$ was precipitated with anti-TTR IgG (see Methods for details). Binding to heterozygous $\mathrm{Thr}^{109}$ TTR (THR 109) is indicated in the open symbols and to normal TPBA (WT) in the closed symbols. (Right) Scatchard analysis of equilibrium competitive binding data. Data obtained with $\mathrm{Thr}^{109}$ TTR are shown in the open symbols and with normal TTR in the closed symbols.
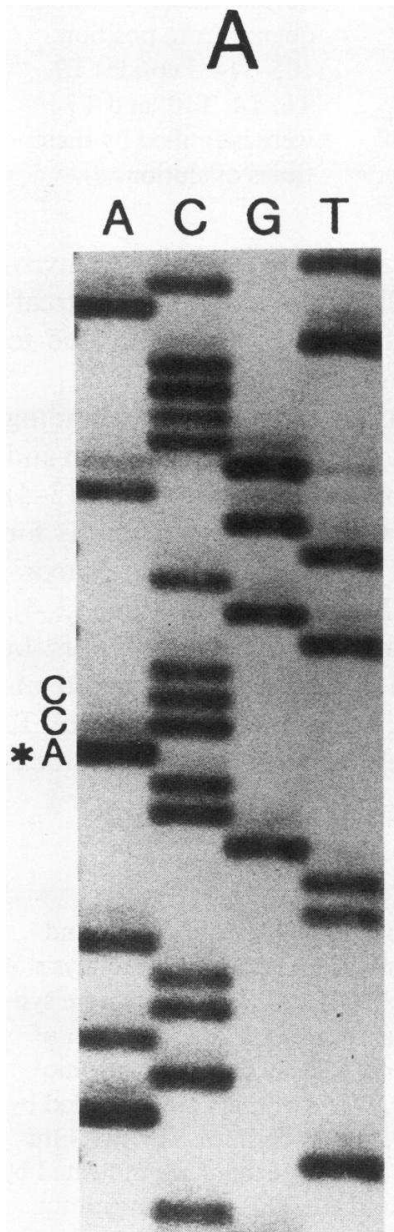

Figure 7. DNA sequencing ladder of exon 4 from the proband's PCR amplified genomic DNA. DNA sequencing was performed on individual M13 clones derived from PCR amplification of TTR exon 4 of the proband's genomic DNA. $(A)$ Results from one of four clones demonstrating the mutation; $(B)$ a normal sequence from another clone in this individual. Four of eight sequenced clones of exon 4 expressed the adenine-for-guanine substitution.
Pro-Tyr and confirmed a threonine-for-alanine substitution at position 109. The HPLC chromatogram also contained a peptide 11-12' found in wild-type TTR which on sequencing revealed alanine at position 109 . Thus, a single heterozygous threonine-for-alanine substitution at position 109 of TTR is associated with an increased affinity of this protein for $T_{4}$ and appears to account for the clinical syndrome of euthyroid hyperthyroxinemia in this kindred.

The adenine-for-guanine substitution in the mutant TTR DNA should abolish one of two cleavage sites for the restriction endonuclease Fnu 4H I in exon 4 (Fig. 9). Thus, digestion with Fnu 4H I of mutant allele DNA amplified from exon 4 would yield only two fragments, while digestion of exon 4 DNA amplified from the normal allele would yield three DNA fragments. As seen in Figs. 8 and 9, when visualized after agarose gel electrophoresis, the largest of these fragments are 222 and 207 bp for the mutant and normal alleles, respectively. To verify that each family member who demonstrated increased binding of ${ }^{125} \mathrm{I}_{-} \mathrm{T}_{4}$ to TTR had the predicted mutation, we subjected DNA from the proband, four additional affected family members, one unaffected relative, and three normal controls to RFLP analysis of amplified exon 4 as detailed in Methods. The results of three affected family members (including the son of the propositus [individual III 2, Fig. 5]), one control, and one unaffected family member are shown in Fig. 10. Based on this analysis, five of five of the individuals predicted to have a threonine-for-alanine substitution have this substitution and none of the unaffected individuals display the loss of the Fnu 4H I site. Each affected individual also appears to be a heterozygote since both the 222- and 207-bp bands were present after Fnu 4H I digestion (Fig. 9).

\section{Discussion}

Euthyroid hyperthyroxinemia is a relatively common clinical condition. Most often, elevated serum thyroxine levels are due to increased levels of TBG, but this situation usually is recognized easily due to the presence of a low $T_{3} R U$ or high TBG level, either of which are part of the routine assessment of 


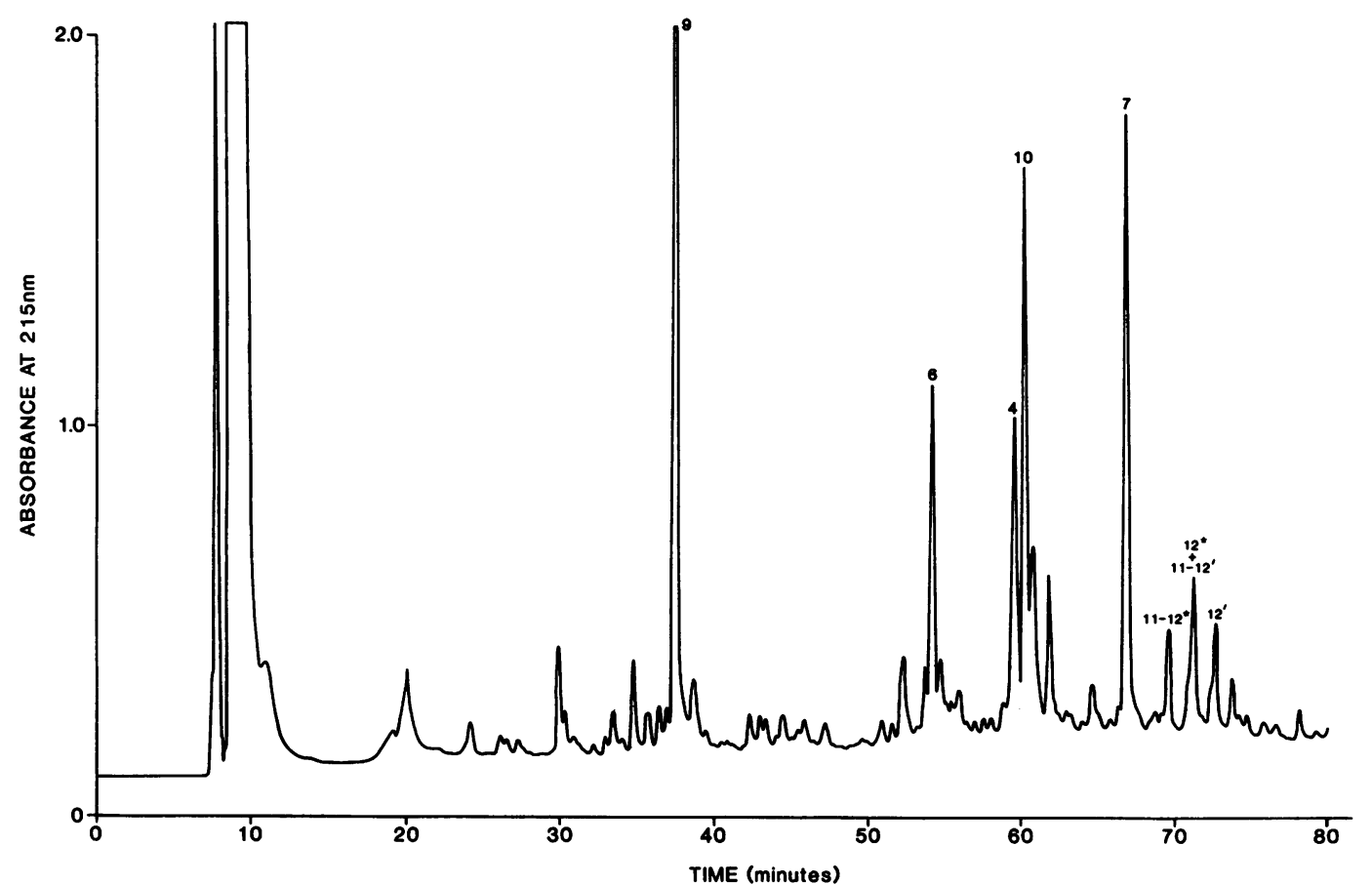

Figure 8. Reverse-phase HPLC chromatogram of tryptic peptides from the propositus' purified TTR. Reverse-phase HPLC separation of peptides derived from trypsin digestion of $\mathbf{3} \mathbf{~ m g}$ of proband's plasma transthyretin. Peptide 11-12* gave the amino acid sequence of the transthyretin peptide 104-114 with a threonine at position 109. Peptide $12^{*}$ gave the transthyretin sequence of transthyretin amino acid residues 105-114 with threonine at position 109. Peptide 11-12' gave the normal transthyretin sequence from positions 104-114 and peptide $12^{\prime}$ gave the normal transthyretin sequence from position 105-114. Peptides T9, T6, T4, T10, and T7 were identified by their times of elution. thyroid status. Euthyroid hyperthyroxinemia associated with a normal $T_{3} R U$ is an uncommon condition caused either by increased $T_{4}$ binding to albumin, transthyretin, or gamma globulin (8). These situations can present diagnostic dilemmas since the elevated total $T_{4}$ and normal $T_{3} R U$ result in an increased free $T_{4}$ index consistent with thyrotoxicosis. Measured free $\mathrm{T}_{4}$ and TSH should be normal. Most patients with this condition have increased binding to albumin, due to a variant albumin with an increased affinity for $T_{4}(17-19)$. The molecular basis of the increased affinity of albumin for $T_{4}$ is unresolved (20). Increased binding of $\mathrm{T}_{4}$ to $\mathrm{IgG}$ most often is seen in the setting of autoimmune thyroid disease such as Hashimoto's thyroiditis (21). From the perspective of clinical management, the increasing availability of sensitive TSH assays to assess suppression of TSH as an aid in the diagnosis of thyrotoxicosis should decrease the likelihood of inappropriate treatment of subjects with euthyroid hyperthyroxinemia due to abnormal or excess $T_{4}$ binding proteins.

Euthyroid hyperthyroxinemia due to increased $T_{4}$ binding to transthyretin is a rare cause of an uncommon condition and may result from an excess mass of normal transthyretin (2-4) or from a transthyretin molecule with an increased affinity for thyroxine (1, 5-7). Three reports of euthyroid hyperthyroxinemia due to elevated levels of TTR have been described (2-4); all cases were in patients with pancreatic endocrine tumors. In several cases, TTR was identified by immunohistocytochemical staining of the tumor tissue $(3,4)$. In these patients, total $\mathrm{T}_{4}$ and $\mathrm{FT}_{4} \mathrm{I}$ concentrations were elevated modestly, the mea-
F1 F2 $\begin{array}{r}109 \\ A C C\end{array}$

5' TAG IGTG GTA TTC ACA GCC AAC GAC TCC GGC CCC CGC CGC TAC ACC ATT GCC GCC ATC ICAC CAT AAg TGT CGG TTG CTG AGG CCG GGG GCG GCG ATG TGG TAA CGG CGG

CTG CTG AGC CCC TAC TCC $(\ldots \ldots 168$ bP ..... CAT TCC TGT GAA AGG C]AC GAC GAC TCG GGG ATG AGG $\{\ldots \ldots 168$ bP .... $\}$ GTA AGG ACA CTT TCC GITG

PRIMER SETS ARE UNDERLINED

ACC CODON FOR THRIO9 MUTATION

F1: FIRST FRU4H I RECOGNITION SITE (GC/NGC) IN EXON 4

F2: SECOND FNU4H I RECOGNITION SITE IN EXON 4

FnU4H I DIGESTION OF NORMAL TTR: 207,35 , and 15 bP FRAGMENTS

FnU4H I DIGESTION OF MUTANT TTR: 222 and 35 bP FRAGMENTS
Figure 9. DNA sequence around exon 4 utilized for RFLP analysis of $\mathrm{Thr}^{109}$ TTR. Two primers were synthesized for PCR amplification of exon 4 and surrounding intronic DNA. The primers are indicated by the solid underlines. The two Fnu 4H I sites in exon 4 are indicated by $F 1$ and F2. The ACC substitution for GCC encoding amino acid residue 109 also is indicated. After amplification with these primer sets, digestion of the full-length, 257-bp exon 4 with Fnu 4H I would yield fragments of 207, 15, and 35 bp for normal TTR and 222 and 35 bp for mutant TTR exon 4. 


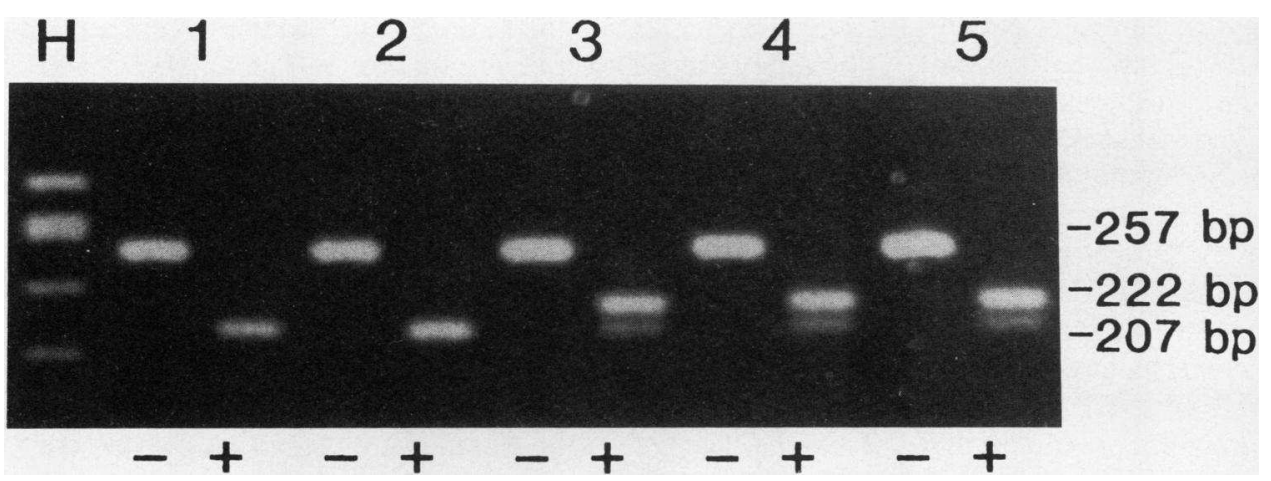

Figure 10. Agarose gel electrophoresis of PCR amplified TTR exon 4 after Fnu 4H I digestion in normal and affected family members. Exon 4 of genomic DNA was amplified with primer sets described in Fig. 8 and in Methods. The amplified cDNA (257 bp in length) was subjected to digestion with Fnu 4H I and the products were run on $4 \%$ agarose, stained with ethidium bromide, and photographed. Each sample was run in duplicate with the left lane ( - ) being in the absence of Fnu 4H I and the right panel $(+)$ in the presence of Fnu 4H I. (Lanes 1 and 2) Exon 4 amplified from two normal controls; (lanes 3-5) exon 4 amplified from three affected family members as defined by immunoprecipitation with anti-TTR IgG. Two additional affected family members gave results identical to those shown in lanes 3-5. The molecular size markers are $\Phi$ X174 RF DNA cut with HAE III and are in the left lane.

sured free $\mathrm{T}_{4}, \mathrm{TSH}$, and $\mathrm{T}_{3}$ concentrations were normal, and the TTR concentrations were elevated strikingly (from 4 to 10 times normal). In one patient in whom TTR binding capacity and affinity were studied in whole sera subjected to agarose gel electrophoresis, the maximal binding capacity for $T_{4}$ was elevated, while the affinity for $\mathrm{T}_{4}$ was normal (4). Thus, it would seem that in these patients hyperthyroxinemia is due to increased binding of $\mathrm{T}_{4}$ to a markedly elevated level of TTR with normal affinity for $\mathrm{T}_{4}$.

In 1982 we presented a preliminary report of the first case of euthyroid hyperthyroxinemia due to a TTR with an apparent increased affinity for $T_{4}(1)$. We described a patient with elevated serum $\mathrm{T}_{4}$ and $\mathrm{FT}_{4} \mathrm{I}$ but with a normal total serum $\mathrm{T}_{3}$, $\mathrm{FT}_{4}$, TSH, and TSH response to TRH. As measured by electrophoresis and immunoabsorption, this patient had an unusually high fraction of $\mathrm{T}_{4}$ associated with TTR. Though this patient's TTR concentration was slightly elevated $(66 \mathrm{mg} / \mathrm{dl})$, the patient's hyperthyroxinemia was thought to be unrelated to the increased TTR concentrations, because the $T_{4}$ binding capacity of the serum TTR was normal, and the patient's son had a similar phenotype with a normal serum TTR concentration. At that time, we had no direct evidence that the patient's TTR had an increased affinity for $T_{4}$ and we had not investigated the molecular basis of this abnormality. We now report results confirming an increased affinity of TTR for $\mathrm{T}_{4}$ and demonstrating a point mutation in the coding region of TTR DNA which probably accounts for this increased affinity and the mode of inheritance of this mutation.

The use of anti-TTR IgG allowed us to isolate ${ }^{125} \mathrm{I}-\mathrm{T}_{4}$ bound to TTR from other thyroxine binding proteins in serum and served as a convenient means to identify affected individuals in the kindred. Affected family members were defined on the basis of the precipitation of ${ }^{125} \mathrm{I}_{-} \mathrm{T}_{4}$ by anti-TTR IgG $>3$ SDs above the mean for sera from six normal control subjects. 8 of 27 family members tested carried the mutant TTR gene based on this definition and as confirmed by a $T_{4}$-loaded $T_{4}$ charcoal-uptake test and by paper electrophoresis (on 7 of the 8 affected family members). It is interesting to note that only five of the eight affected family members had total $\mathrm{T}_{4}$ levels above the upper limit of normal.

Each of the individuals tested demonstrated an increased affinity of TTR for $\mathrm{T}_{4}$ as assessed by competitive binding assays using whole sera. For the proband, this affinity was three times greater than that of normal TTR and was confirmed with competitive binding studies performed with purified TTR. The available data support the concept that each affected individual is heterozygous for this mutation and that the mutation is transmitted in an autosomal dominant fashion. None of the members of this kindred have been treated for thyrotoxicosis and none except the proband had evidence of a goiter. Based on the presence of a variant TTR molecule with increased affinity for thyroxine we propose that this syndrome be called euthyroid dystransthyretinemic hyperthyroxinemia.

Since investigation into the molecular basis of the increased affinity of TTR for $\mathrm{T}_{4}$ not only can establish the molecular basis of euthyroid dystransthyretinemic hyperthyroxinemia but also can provide some further insight into the nature of the molecular interaction between $T_{4}$ and TTR, we performed sequencing studies on both the TTR gene and protein in the proband of this kindred. DNA and protein sequencing both are consistent with a threonine-for-alanine substitution in amino acid residue 109 of TTR. This is due to an adenine-for-guanine substitution at the first base pair of the codon for amino acid residue 109 in exon 4 of the TTR gene. All five affected family members who were tested were heterozygous for this mutation based on RFLP analysis of PCR-amplified exon 4 of genomic DNA digested with the restriction enzyme Fnu 4H I. While absolute proof of the relationship between this threonine-for-alanine substitution will require direct testing of homozygous, recombinant TTRs, the lack of other detectable defects in the coding region of TTR makes it likely that this mutation is responsible for the increased affinity of TTR for $\mathrm{T}_{4}$.

Others have reported similar cases of hyperthyroxinemia due to a TTR with increased affinity for thyroxine. One case of euthyroid hyperthyroxinemia due to an increased fraction of $\mathrm{T}_{4}$ associated with TTR as assessed by immunoprecipitation was reported by Croxson et al. (7). Since the patient had only a trivial elevation of his TTR concentration, Croxson et al. attributed the hyperthyroxinemia to an abnormal TTR with an increased affinity for thyroxine, though direct studies to verify this assumption were not undertaken. In 1984, Lalloz et al. (5) reported a patient with dystransthyretinemic hyperthyroxinemia with normal TTR concentrations. They were able to 
isolate this patient's TTR and show that it had an increased affinity for thyroxine and reverse $\mathrm{T} 3$ as determined by equilibrium dialysis. Subsequently, Lalloz et al. (6) reported a patient who had both dysalbuminemic and dystransthyretinemic hyperthyroxinemia. They were able to verify that both the patient's albumin and TTR had an increased affinity for thyroxine. In addition, they were able to show that these abnormalities were inherited independently in the patient's family as autosomal dominant traits. Further studies on one of these dystransthyretinemic patients were reported in abstract form by Fitch et al. (22). In this patient, a heterozygous point mutation in exon 2 encodes a serine-for-glycine substitution at amino acid number 6 in the mature protein.

These are not the only examples of mutant TTRs with altered affinity for thyroxine. Refetoff et al. (23) have examined the affinity of TTR for $T_{4}$ in patients with familial amyloidotic polyneuropathy secondary to defined mutations in TTR (23). While none of these mutant TTRs demonstrated increased affinity for $T_{4}$, several demonstrated decreased affinity for $T_{4}$. We have confirmed this finding and extended it to additional TTR mutants using the ${ }^{125} \mathrm{I}_{-} \mathrm{T}_{4}$ equilibrium competitive binding assay (24). Thus, a range of point mutations in the TTR gene alter the ability of TTR molecules to associate with one another (to produce amyloid) and to associate with thyroxine. Each of these different mutations provides further insight into the molecular association of TTR with thyroxine.

It is interesting to speculate how mutation of $\mathrm{Ala}^{109}$ to $\mathrm{Thr}^{109}$ described here affects TTR's affinity for $\mathrm{T}_{4}$. Amino acid 109 is situated at a domain that could perturb thyroxine binding in several different ways. The $3^{\prime}$ outer ring iodine of thyroxine is projected to associate with the backbone oxygen of $\mathrm{Ala}^{109}(25,26)$. It is not clear how the substitution of threonine for alanine at this position alters the association with thyroxine iodine. The methyl groups of $\mathrm{Ala}^{108}$ and $\mathrm{Leu}^{110}$ are thought to form part of the hydrophobic patch of the thyroxine binding site (25), and it is possible that a substitution in the amino acid between them might slightly alter the relationship of these amino acids and alter thyroxine binding. It also is possible that the hydroxyl side chain of $\mathrm{Thr}^{109}$ participates directly in the binding of $T_{4}$. Alternatively, Blake et al. (26) reported that $\mathrm{Ala}^{109}$ forms hydrogen bonds with Lys, ${ }^{15}$ a residue that interacts with the side chain carboxylate of $T_{4}$. Thus, it also is possible that a threonine-for-alanine substitution at amino acid 109 might result in some alteration in the configuration of Lys $^{15}$ vis-a-vis $T_{4}$. Clarification of the mechanism by which this mutation increases TTR's affinity for $T_{4}$ will be possible with subsequent molecular modeling and crystallization of homozygous mutant TTR. Additional information also may come from binding studies with iodothyronine analogues.

In the family described here, TTR has a threefold increased affinity for $T_{4}$ compared with normal TTR. Yet, the affected individuals are heterozygous for the mutant and normal TTR. Normal TTR is a tetrameric protein comprised of four identical subunits. In the affected individuals, assuming that the mutation will not affect the association of normal and mutant monomers, we would predict that TTR in the circulation is heterogeneous and consists of molecules with varying proportions of normal and mutant monomers. Thus, in these studies we have measured $T_{4}$ affinity to TTR molecules, the majority of which $(93.75 \%$ based on random association of TTR monomers) contain at least one normal monomer. It is possible that
TTR tetramers consisting of four mutant monomers have even a higher affinity for $T_{4}$ than measured in our competitive binding assays. Direct determination of $\mathrm{T}_{4}$ affinity by homozygous mutant TTR will have to await recombinant expression of this protein and should provide additional clues about the molecular interaction between TTR and thyroxine and about the association of TTR monomers themselves.

\section{Acknowledgments}

This work was supported by a grants from the Milton Foundation, The Arthritis Foundation, The Grace M. Showalter Trust, The Marion E. Jacobson Fund, by National Institutes of Health grants DK-18416, DK-34881, AR-20582, AR-7448, RR-00750, and by V. A. Medical Research.

\section{References}

1. Moses, A. C., J. Lawlor, J. Haddow, and I. Jackson. 1982. Familial euthyroid hyperthyroxinemia resulting from increased thyroxinebinding prealbumin. N. Engl. J. Med. 306:966-969.

2. Rajatanavin R., C. Liberman, G. D. Lawrence, C. M. D'Arcangues, R. A. Young, and C. H. Emerson. 1985. Euthyroid hyperthyroxinemia and thyroxine-binding prealbumin excess in islet cell carcinoma. J. Clin. Endocrinol. Metab. 61:17-21.

3. Jacobsson, B., T. Pettersson, B. Sandstedt, and A. Carlstrom. 1979. Prealbumin in the islets of Langerhans. IRCS (Int. Res. Commun. Syst.) Med. Sci. 7:590.

4. Maye P., A. Bisetti, A. Burger, R. Docter, R. Gaillard, M. Griessen, and M. F. Pelte. 1989. Hyperprealbuminemia, euthyroid hyperthyroxinemia, Zollinger-Ellison-like syndrome and hypercorticism in a pancreatic endocrine tumor. Acta Endocrinol. 120:87-91.

5. Lalloz, M. R. A., P. G. H. Byfield, and R. L. Himsworth. 1984. A prealbumin variant with an increased affinity for $T_{4}$ and reverse- $T_{3}$. Clin. Endocrinol. 21:331-338.

6. Lalloz, M. R. A., P. G. H. Byfield, K. M. Goel, M. M. Loudon, J. A. Thomson, and R. L. Himsworth. 1987. Hyperthyroxinemia due to the coexistence of two raised affinity thyroxine-binding proteins (albumin and prealbumin) in one family. J. Clin. Endocrinol. Metab. 64:346-352.

7. Croxson, M. S., B. N. Palmer, I. M. Holdaway, P. A. Frengley, and M. C. Evans. 1985. Detection of familial dysalbuminemic hyperthyroxinemia. Br. Med. J. 290:1099-1102.

8. Stockigt, J. R., S. A. Dyer, V. S. Mohr, E. L. White, and J. W. Barlow. 1986. Specific methods to identify plasma binding abnormalities in euthyroid hyperthyroxinemia. J. Clin. Endocrinol. Metab. 62:230-233.

9. Duvulet, F. E., and M. D. Benson. 1983. Polymorphism of human plasma thyroxine binding prealbumin. Biochem. Biophys. Res. Commun. 114:657-662.

10. Scatchard, G. 1949. The attraction of proteins for small molecules and ions. Ann. NY Acad. Sci. 51:660-672.

11. Nichols, W. C., J. J. Liepnieks, V. A. McKusick, and M. D. Benson. 1989. Direct sequencing of the gene for Maryland/German Familial Amyloidotic Polyneuropathy Type 2 and genotyping by allele-specific enzymatic amplification. Genomics. 5:535-540.

12. Strauss, W. M. 1987. Preparation of genomic DNA from mammalian tissue. In Current Protocols in Molecular Biology. F. M. Ausubel, editor. John Wiley and Sons, Inc., Boston. 2.2.1-2.2.2.

13. Tsuzuki, T., S. Mita, S. Maeda, S. Araki, and K. Shidama. 1985. Structure of the human prealbumin gene. J. Biol. Chem. 260:12224-12227.

14. Kanda, Y., D. W. Goodman, R. E. Canfield, and F. J. Morgan. 1974. The amino acid sequence of human plasma prealbumin. J. Biol. Chem. 249:6796-6805. 
15. Moller, D. E., A. Yokota, and J. S. Flier. 1989. Normal insulin-receptor cDNA sequence in Pima Indians with NIDDM. Diabetes 38:1496-1500.

16. Sanger, F., S. Nicklen, and A. R. Coulson. 1977. DNA sequencing with chain-terminating inhibitors. Proc. Natl. Acad. Sci. USA. 74:5463-5467.

17. Stockigt, J. R., D. J. Topliss, J. W. Barlow, E. L. White, D. M. Hurley, and P. Taft. 1981. Familial euthyroid thyroxine excess: an appropriate response to abnormal thyroxine binding associated with albumin. J. Clin. Endocrinol. Metab. 53:353-359.

18. Ruiz, M., R. Rajatanavin, R. A. Young, C. Taylor, R. Brown, L. E. Braverman, and S. H. Ingbar. 1982. Familial dysalbuminemic hyperthyroxinemia, a syndrome that can be confused with thyrotoxicosis. N. Engl. J. Med. 306:635-639.

19. Yeo, P. P. B., Y. Yabu, J. R. Etzkorn, R. Rajatanavin, L. E. Braverman, and S. H. Ingbar. 1987. Familial dysalbuminemic hyperthyroxinemia: a four generation study. J. Endocrinol. Invest. 10:33-38.

20. Yabu, Y., S. M. Amir, M. Ruiz, L. E. Braverman, and S. H. Ingbar. 1985. Heterogeneity of thyroxine binding by serum albumins in normal subjects and patients with familial dysalbuminemic hyperthyroxinemia. J. Clin. Endocrinol. Metab. 60:451-459.

21. Premachandra, B. N., J. Ginsberg, and P. G. Walfish. 1980.
Binding of reverse $\mathrm{T} 3$ to serum immunoglobulins in man and in the rabbit. J. Clin. Endocrinol. Metab. 50:802-805.

22. Fitch N. J. S., M. T. Akbari, M. C. Sheppard, and D. B. Ramsden. 1989. Serine-for-glycine substitution at position 6 in an inherited, non-lethal transthyretin variant with increased thyroxine-binding affinity. First International Symposium on Hereditary Amyloidosis, September 1989, Oporto, Portugal.

23. Refetoff, S., F. E. Dwulet, and M. D. Benson. 1986. Reduced affinity for thyroxine in two of three structural thyroxine-binding prealbumin variants associated with familial amyloidotic polyneuropathy. J. Clin. Endocrinol. Metab. 63:1432-1437.

24. Rosen, H. N., M. D. Benson, J. J. Liepnieks, G. Holmgren, O. Sandgren, L. Steen, and A. C. Moses. 1990. Thyroxine interactions with transthyretin: a comparison of 10 different naturally occurring transthyretin variants. 10th International Thyroid Congress, Jerusalem, Israel, 9-14 September 1990.

25. Blake, C. C., and S. J. Oatley. 1977. Protein-DNA and proteinhormone interactions in prealbumin: a model of the thyroid hormone nuclear receptor? Nature (Lond.). 268:115-120.

26. Blake, C. C. F., M. J. Geisow, and S. J. Oatley. 1978. Structure of prealbumin: Secondary, tertiary, and quaternary interactions determined by fourier refinement at 1.8 A. J. Mol. Biol. 121:339-356. 